Revista de la red interuniversitaria de estudios sobre las literaturas rioplatenses contemporáneas en Francia

$22 \mid 2021$

¿Cómo se cuenta una vida? El retorno de lo biográfico en la literatura rioplatense contemporánea

\title{
Néstor Sánchez y Osvaldo Baigorria: una amistad posible
}

Néstor Sánchez et Osvaldo Baigorria : une amitié possible.

Néstor Sánchez and Osvaldo Baigorria: a possible friendship.

Julia Musitano

\section{OpenEdition}

Journals

Edición electrónica

URL: http://journals.openedition.org/lirico/10363

DOI: $10.4000 /$ lirico. 10363

ISSN: 2262-8339

Editor

Réseau interuniversitaire d'étude des littératures contemporaines du Río de la Plata

Referencia electrónica

Julia Musitano, «Néstor Sánchez y Osvaldo Baigorria: una amistad posible», Cuadernos LIRICO [En

línea], 22 | 2021, Publicado el 11 marzo 2021, consultado el 16 marzo 2021. URL: http://

journals.openedition.org/lirico/10363 ; DOl: https://doi.org/10.4000/lirico.10363

Este documento fue generado automáticamente el 16 marzo 2021.

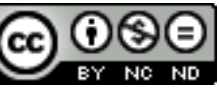

Cuadernos LIRICO está distribuido bajo una Licencia Creative Commons Atribución-NoComercialSinDerivar 4.0 Internacional. 


\title{
Néstor Sánchez y Osvaldo Baigorria: una amistad posible
}

\author{
Néstor Sánchez et Osvaldo Baigorria : une amitié possible. \\ Néstor Sánchez and Osvaldo Baigorria: a possible friendship.
}

\section{Julia Musitano}

Será necesario, de todos modos, no olvidarlo: este
proyecto no se me ha ocurrido a mí. Me lo
susurraron después de un almuerzo. Poco faltó
para poder decir que se trató de un encargo. Pero
¿qué es un encargo del que uno se apropia tan
deprisa sino otro nombre para el deseo? El
nombre del deseo del otro justo antes de que se
haga suyo (Peeters, Tres años con Derrida).

Desde el inicio, en Sobre Sánchez, Osvaldo Baigorria se desencuentra con Néstor Sánchez. Todo surge por un encargo editorial que se torna conveniente para empezar una investigación y escribir una biografía. Baigorria no lo conocía a Sánchez antes de eso, no había leído nada de Sánchez, no sabía quién era. Un encargo editorial y una vieja foto son, sin embargo, suficientes para darle la bienvenida a un desconocido, para habilitarle la entrada a quien va a cambiarle el modo de pensar la vida y de hacer literatura.

Para Baigorria, ese encuentro de entrada fallido y la posterior escritura de una biografía no tan biografía - "de biografía fallida a ensayo colapsado con astillas de novela a medio terminar a postautobiografía" (2012: 7) - tuvieron consecuencias. Hacia atrás y hacia adelante, la literatura de Baigorria sufrió un proceso de transformación. Hacia atrás: Baigorria revisa viejas categorías con las que trabajaba para "amigarse" con Sánchez y poder escribir sobre él (Anarquismo trashumante y Llévatela amigo). Hacia adelante: todo lo que escribe Baigorria después de la biografía (Postales de contracultura e Indiada) está habitado por la figura de Sánchez. Por eso me interesa rastrear cuáles son los rasgos que hicieron posible una amistad entre Sánchez y Baigorria, y los motivos 
por los que la literatura de uno se ve contaminada por la literatura de otro cuando la vida se atraviesa.

3 A pesar de no poder encontrar una definición que le haga justicia al género, los textos teóricos sobre biografías parecen estar de acuerdo en una cosa: durante el proceso de investigación y escritura se establece, de cualquier manera, un vínculo entre biógrafo y biografiado; y para que el resultado sea aceptable "los biógrafos deben luchar constantemente para que sus sujetos no se apoderen de ellos y para no enamorarse de ellos" (Edel 1990: 22). Y para eso, debe haber control sobre el yo biográfico. Podríamos comenzar diciendo que esa primera batalla está perdida para Baigorria, que se dejó embarrar hasta las rodillas en una casa aislada en el Tigre con la estricta (aunque perezosa) voluntad de hacer algo con Sánchez. Para escribir la biografía, se instala en esa casa que compró con un dinero de la venta de la de sus padres pensando que estar aislado sería beneficiosos para el proceso de construcción de la biografía. El lugar en el que se escribe (la locación) y la escritura como movimiento se cruzan constantemente a lo largo de todos sus textos.

Baigorria dijo sí al encargo sin saber nada de Sánchez: una foto de un lumpen que ilustraba un discurso de Sánchez resumía la imagen equívoca que Baigorria se hacía del escritor nómade. Sánchez, que se había ido sin dejar huellas y que vivió como clochard durante tantos años en Estados Unidos, no parecía un hippie; "era la cara de un cuerpo típico de la generación anterior. Un tanguero" (2012: 11). La biografía comienza con el equívoco, con una idea errada; comienza cuando biógrafo y biografiado aún no se conocen. Aunque el biógrafo ya sabe, de antemano, que aun sin estar preparado, le abrirá las puertas de su casa del Tigre y lo dejará entrar.

\section{El escritor recibe un huésped inesperado}

5 En un artículo anterior (Musitano 2018) resaltaba el hecho de que Baigorria no quiso (o no pudo) seguir el rastro de una trayectoria de vida y de una obra o un pensamiento cuando encaró el proyecto de escribir sobre Sánchez. Me intrigó la idea de que, en la primera biografía, en la única biografía sobre el misterioso escritor que desapareció sin dejar huellas, no íbamos a encontrarnos con la cronología de una vida sino con su mayor enigma: ¿por qué Sánchez se fue?, ¿por qué dejó de escribir? Baigorria prefería no escribir la vida de Sánchez, sino poner el acento en su renuncia indeclinable a seguir haciendo literatura. Intenté responder a esa pregunta en un diálogo con la definición de biografía literaria. Ahora, en esta segunda lectura de la biografía, se impone otro interrogante: ¿Cómo es que Baigorria no conocía a Sánchez? El escritor de Anarquismo trashumante. Crónica de crotos y linyeras no conocía al croto que había caminado las mismas rutas por las que él caminaría unos años después; el clochard podría haber sido protagonista de ese libro, pero Baigorria "no había leído una sola palabra escrita por Sánchez" (2012: 84). A Baigorria, que incluso estaba muy al tanto de los consejos del líder espiritual Gurdjieff ${ }^{1}$-gran transformador de la vida y el pensamiento de Sánchez -, de todas formas, Sánchez "lo volvió loco", "no entendía nada". El autor de Llévatela amigo por el bien de los tres que cuenta los avatares de un vínculo amoroso entre dos mujeres y un varón, no había leído Ley de tres de Sánchez que cuenta lo mismo.

Cómo llegué hasta allí y cómo luego terminaría aquí escribiendo sobre Sánchez es un largo cuento. Baste decir por ahora que en la misma época en que conocí a aquel primer lumpen-comunista dejé de estudiar periodismo, me hice artesano en cuero y en metal, y con esas artesanías y bisuterías financié mi viaje de tres años de 
duración por carretera desde la América del Sur hasta la del Norte, tironeado por un imán parecido al que habrá sentido Néstor Sánchez cuando marchó a California.

0 eso creo. (2012: 82)

6 Esos dos que estaban tironeados por el mismo imán, que habían recorrido los mismos caminos del norte, en busca de algo de lo que no sabemos mucho, no se habían encontrado. Tal como a Peeters con Derrida en el epígrafe, a Baigorria le susurran el nombre de Sánchez. Y solo hizo falta eso para que se produzca el hechizo y no haya vuelta atrás. Ahora bien, para que el deseo ajeno se haga propio, para que un escritor se encuentre con otro y se dedique durante años a desandar sus pasos, un nombre al oído tiene el carácter de lo afectivo, de lo azaroso, del acontecimiento.

El modo y el momento en que un escritor encuentra a otro -entiende Luis Chitarroni- no es siempre el mejor ni el oportuno. La admiración, preeminente entre las bajas pasiones, tiene, para llevar a cabo su tarea, que ser sometida a una larga serie de incidencias o accidentes: un aniversario o una efeméride, el interés de un editor, la indolencia clásica de la vida... (1997: 14)

7 Como me interesa rastrear los rasgos que hicieron posible una amistad entre Sánchez y Baigorria, voy a partir de la hipótesis de que cuando un escritor decide inmiscuirse en una vida ajena tiene que hacerla propia. Si no hay nada en común, habrá que inventarlo. Biógrafo y biografiado se hacen amigos, sin proximidad, sin reciprocidad. Son amigos del porvenir. En el caso de Baigorria y Sánchez, el lazo se hace evidente y la extrañeza reside, en todo caso, en que no se haya producido un encuentro antes. Por eso, la biografía está construida de tal forma que una vida se come a la otra: el último capítulo, que está planteado como notas al pie, es la vida de Baigorria que emerge a partir de la de Sánchez ${ }^{2}$. Baigorria le abrió la puerta a un desconocido, alguien llegó a su vida para ponerlo a prueba.

No contaba con el desvío al que me llevaría la búsqueda de ese rastro ni las reflexiones (reflejos, ecos mentales) que me harían evocar mis propias búsquedas y encuentros en los años 60 y 70 en una riada que fluía hacia la costa oeste de América. (89)

Claro que no contaba con el desvío, se va a pique, se descontrola porque no estaba preparado para recibirlo, porque la llegada de Sánchez irrumpe sin pedir permiso, atraviesa el umbral de la casa de Tigre para quedarse y para transformarlo todo. Baigorria pierde el rumbo y para restituirle cohesión de vida a una narración que de por sí es elíptica y anuladora, tiene dos opciones: domesticar esa vida y armar cronología (una vida ajena que quiera ser relato se administra y se controla) o aventurarse en la forma. La forma se dispersa y el biógrafo no busca la rigurosidad del relato sino que va al encuentro con su propia vida y sus afectos. Baigorria opera con lo que tiene al alcance de su mano. No realiza una investigación exhaustiva, no acude a documentos y a infinidad de testimonios, recurre a sí mismo.

Me voy de tema, pierdo la pista, me deslizo o desbarranco, parte de los efectos de acercarme a una figura tan extrema de escritor o ex escritor como la que tengo enfrente, es el derrape. Quizá no estaba preparado para encarar la tarea, no tenía el training, la sensibilidad adecuada. Igual yo remo. (12)

9 Si nos atenemos a la noción de hospitalidad postulada por Jacques Derrida, es preciso que Baigorria no esté preparado para acogerlo. La hospitalidad implica acoger más allá de la propia capacidad para hacerlo. Biógrafo y biografiado tienen que hacerse amigos: Sánchez lo eligió mucho antes de que Baigorria pudiera elegirlo a él; y el dueño de casa está obligado a responder el llamado. Puede desobedecerlo, pero no escapar: "No tengo más remedio que intentarlo" (25). Incluso, responde Anne Dufourmantelle (2018) en un 
diálogo con Derrida, la hospitalidad se ofrece mucho antes que el otro se identifique, se recibe sin preguntas y sin condiciones. "De modo que cuando recibí el encargo de escribir sobre Sánchez acepté sin pensarlo mucho" (88). Baigorria está obligado obligado porque una vez que le susurraron el nombre, se prohíbe la indiferencia, no hay escapatoria: "Cada tanto, cuando algo me sale mal o fastidia (siempre hay algo), repito como mantra: sánchez, sánchez, no te enganches. Igual fracaso, me engancho" (164) - a recibir algo más grande, más duradero y poderoso que lo pondrá a prueba.

Para definir el amor como un encuentro azaroso, Alain Finkielkraut señala que la irrupción del otro nos conmueve, nos estorba o nos pilla en falta. En Sobre Sánchez, esa "o" se convierte en "y": Baigorria está no solo movilizado por semejante figura sino molesto, protestón y desbordado. Se podría decir que Baigorria ama a Sánchez a regañadientes. En la página 88 , al principio: "me pareció que tenía varias cosas en común con el nómade", al final: "La apresurada identificación con el autor de Nosotros dos se esfumó apenas me puse a leer sus libros... Experimentación total, pérdida de autoconciencia en la lectura, sonido de saxo pero ¿qué carajo dice?”. Como a todo enamorado, el amor le sucedió a pesar suyo: solo necesitaba el dinero del encargo y sin desearlo ni preverlo, una vida ajena estalló en el interior de su casa para dejar esquirlas por doquier, y confinarlo en un proyecto de escritura que le costará su salud mental y dejará secuelas en la propia literatura. Quiero decir que cuando hablamos de amor no nos referimos a sentimentalismos, sino a una fuerza que nos trasciende, que nos ata y simultáneamente nos libera. Un amor que lucha por hacer inofensivo al otro para no dejarse desbordar por él, un amor que acoge, pero que también desarma (Finkielkraut 1979: 135-160).

11 Un huésped inesperado ha llegado desde afuera, se instala en Baigorria y lo deja desamparado. La violencia con la que el otro irrumpe tiene el poder de enredar al biógrafo en la tarea de descifrar una lengua extranjera como si fuese la más familiar de todas. Baigorria está dispuesto a ir a su encuentro ${ }^{3}$, pero Sánchez marca las distancias y le muestra sólo las incógnitas. La paradoja del amor es tal que no podemos escapar de quien se nos escapa siempre, alega Finkielkraut. Esa búsqueda sintetiza el trabajo de la biografía: el encuentro con lo misterioso de un otro que se debe dar a conocer a pesar de que todos sepamos que el carácter elusivo y discontinuo de una vida no lo habilitará jamás: “...la vida que puede contarse no es la vida auténtica ni la experiencia relatada es la inapelable experiencia. Por eso el Néstor Sánchez sobre el que puede escribirse no es el verdadero Néstor Sánchez" (164).

Derrida señala que huésped proviene del latín hostis, que a su vez significa enemigo. La violencia, entonces, tal como en la raíz latina, es inherente al vínculo y con doble entrada: el biógrafo se ve excedido por la llegada de un otro que lo va a habitar y a su vez, le demanda al biografiado que habite un espacio común. A Baigorria le gustaría ser un enamorado fiel, decir lo que Sánchez quisiera escuchar, pero muy pronto el hippie resulta un tanguero y la identificación se esfuma. Por el lado del biógrafo: Baigorria protesta porque la investigación sobre una vida requiere más esfuerzos que los que sospechaba: "Pero esto lo pensé más tarde, cuando ya estaba metido de cabeza en una investigación que me costaría una serie de pérdidas: dinero, ocupación, rumbo, sentido, tierra firme y salud (también mental)" (11); “A mí también me gustaría cantarle al ocio, pero hay que trabajar mucho para acercarse a la experiencia vivida por otro" (25). Sin embargo, sabe que escribir la vida de otro no implica capturar la verdad sino experimentar en carne propia cuánto tiene de ilusorio ese deseo: "Supuestos, 
conjeturas, nadie sabe, la biografía es un género tramposo: no se puede escribir sobre una vida -a menos que se la toque por encima, como si se improvisara-" (21). Por el lado del biografiado: para que Sánchez sea personaje, Baigorria tiene que serle infiel, tiene que someterlo a un proceso de desapegos y desvíos, tiene que violentarlo para hacerlo ingresar en su propia escritura.

\section{¿Dónde?}

Las formas amorosas en las que acontece la vida en la literatura de Baigorria son el movimiento, el viaje, el despojo, la intemperie, la aventura y el sexo. Son también las formas que encontró en Sánchez (o que hizo lo posible para encontrar) y que Sánchez encontró en él. El encuentro azaroso e inesperado entre dos escritores supone el despliegue de un espacio sostenido. Si revisamos con atención el texto, observaremos que la espacialidad y la geografía ocupan la mayor parte de las páginas. El lugar como aquello que no se posee y el no lugar como aquello que se hace propio son leit motiv de los tres capítulos (además de ser protagonistas en Postales de contracultura e Indiada). Ya mismo, en la segunda página de "Voodoo Child", aparece una dirección postal, que no remite a una casa, un hogar, un lugar, sino más bien al vacío repleto de autos de una playa de estacionamiento. Lo primero que sabemos de Sánchez es que se fue para vivir a la intemperie, que no hay un domicilio donde ir a buscarlo. Si antes decíamos que Sánchez lo eligió a Baigorria mucho antes de que él se enterase, lo decíamos porque, retroactivamente, Anarquismo trashumante (publicado diez años antes) es un libro de, por y para Sánchez. Baigorria no tiene que revisar mucho para que el protagonista de la biografía sea uno de sus crotos coleccionables.

Una aclaración: la huella del vagabundo no es idéntica a la del homeless. Mientras que los habitantes sin techo de toda urbe son una muestra de exclusión extrema, forzada, impuesta por la sociedad de mercado, el croto siguió voluntariamente el rastro que lo llevaría a un lugar de no pertenencia. El croto no se definió por la carencia que implica la preposición "sin". Su estilo fue más la renuncia que el despido. Y más el abandono del hogar que la pérdida de la vivienda. (2012: 17)

¿No sería ese un primer acercamiento a la figura de Sánchez? El biografiado no carece de hogar, anda, camina, ese es su destino. El movimiento es un gesto (no un lugar) a partir del cual el sujeto adviene. En Postales, se lee:

La fiebre del camino sostenía el andar, el deambular, el vivir sin techo fijo. Si no fuese por esa pasión nómade todo hubiera sido más triste, desamparado. [...] Éramos nómades, pertenecíamos a una especie de pura sangre, teníamos el paradójico orgullo de quien aprendía a sobrevivir a riesgo de intemperie. (Baigorria 2018: 41)

Para escribir la biografía, se instala en una casa del Tigre, en una isla, alejada de todo y vulnerable a los cambios climáticos. Aunque, si reparamos en el relato de Postales de contracultura, sabemos que para quien vivió en los bosques canadienses, en pleno invierno, solo en una cabaña, el clima, los animales salvajes y la soledad no son un problema. Sin embargo, la llegada de Sánchez lo modifica todo.

Mi llegada al Tigre coincidió con el inicio de la investigación y de la escritura sobre Sánchez: el delta como forma de sedentarismo, la fantasía de que en la isla se podía hacer una vida-otra. Imaginé que este sería el mejor lugar para escribir (por encargo o por gusto) en general y, en particular, sobre Sánchez. Me equivocaba. (2012: 88) 
Locación y escritura, ya había adelantado: Baigorria pone en evidencia el proceso de escritura en tanto hábitat. Adentro y afuera, resistencia y refugio, la casa, para Baigorria, no es una morada donde descansar, un refugio de los contratiempos de la meteorología, es más bien un negativo, una inversión de la función habitar (Bachelard 2000). Las casas de Baigorria no están herméticamente cerradas, son una continuidad con el afuera, las puertas siempre están entreabiertas. El agua del río y el calor húmedo, como los huéspedes inesperados, pueden fácilmente penetrarla ${ }^{4}$.

Ese encuentro que se propone entre biógrafo y biografiado tiene el carácter de lo azaroso, del acontecimiento. Amor y hospitalidad se actualizan en la escritura de una vida ajena. La hospitalidad, entiende Dufourmantelle, tiene una relación al menos ambivalente con el lugar.

Como si el lugar del que se tratara en la hospitalidad fuera un lugar que no perteneciese originalmente ni al anfitrión ni al invitado, sino al gesto mediante el cual uno da acogida al otro (incluso y sobre todo si uno mismo no tiene morada a partir de la cual pueda ser pensada esta acogida). (2018: 64)

Por eso, la pregunta que abre este parágrafo es por el dónde. ¿Dónde recibir a mi huésped? ¿En mi casa, en un lugar fijo? La autenticidad de la hospitalidad reside, en términos de Dufourmantelle, en la dislocación del sin-abrigo, del sin-lugar propio (60). Más bien, el sujeto adviene en movimiento, en el gesto del intercambio.

El biógrafo pierde mucho en el camino de conocer a Sánchez y se lo atribuye al lugar. Según Postales y según las notas al pie de la biografía, Baigorria es movimiento, es viaje. Y esa vida otra en la que decidió investigar es también escape, intemperie. Baigorria no contaba con dos fugas cuando encaró la empresa: con que una vida se iba a llevar puesta a la otra y la escritura tomaría un rumbo inesperado, y con que no importaba el lugar donde recibiera a Sánchez porque el sedentarismo no los identificaba. "Intento escribir sobre Sánchez, y de pronto hay crecida y el terreno se inunda" (90). Sánchez atraviesa el umbral en movimiento y la quietud de la isla afecta a Baigorria hasta corporalmente. Baigorria y Sánchez habitan la intemperie porque, como dice Gastón Bachelard (2000), están más seguros en las calles donde no habitamos más que de paso.

Hay que cuidarse de no meter el pie en el agujero negro. No caer en la depresión del sedentario, ese aparato de captura con música de tango: "el viajero que huye / tarde o temprano detiene su andar". Esto me pasó a un año de instalarme en la isla, después de soñar con el delta como punto de fuga de la urbe y de sumergir los pies en el barro de un pantano traga nómades. [...] Yo escribía sobre Sánchez cada vez que la isla me dejaba pero me sentía cada vez peor. (2012: 129)

La biografía oscila constantemente entre el adentro y el afuera, la tierra firme y el barro movedizo, el domicilio y la intemperie, el quedarse y el andar. La dirección postal del inicio ya indica la dislocación que contaminará todo el texto. Ir en búsqueda de otro o demandarle a otro que se acerque a uno se define en la espacialidad. ¿Hacia dónde voy? ¿Quién viene? Pareciera ser que Baigorria puede escribir finalmente sobre Sánchez (en el proceso del ir y venir, de salir y entrar a la isla) porque, en palabras de Dufourmantelle (2019:60), sólo aquel que ha soportado la experiencia de la privación del hogar (y deberíamos remitirnos aquí a Anarquismo trashumante para cuestionar el término privación en tanto no responde al carácter voluntario del croto) puede ofrecer hospitalidad.

Que no es falta de techo ni de un plato de comida. Intemperie que es más un sentimiento, algo interior, una desconexión de los que quienes te rodean, de la gente que viaja y vive "como todo el mundo". Por eso un clochard es siempre un 
extranjero, aun en tierra propia. Un exiliado interior. Uno que tal vez quiso estar “ahí". Aunque en verdad no sabía cómo era el "ahí" ni donde lo llevaría. (Baigorria 2008: 96)

Bachelard entiende que es en el corazón del ser donde el ser es errabundo. A veces es fuera de sí donde el ser experimenta consistencias. ¿Estar encerrado en el exterior? ¿o que la intemperie funcione como hábitat, como refugio de la intimidad? ¿Dónde habitar y dónde huir? El exiliado interior, como figura, define a biógrafo y biografiado. La intemperie está afuera, pero también adentro. En la cita, Baigorria relata la decisión de irse de Sánchez, pero podría decir lo mismo de la propia decisión de haber aceptado el encargo. La escritura conlleva riesgos (el extravío) porque implica un salto al vacío (a la intemperie), un salto que enfrenta al escritor con aquello que desconoce de sí mismo. No sabía dónde lo llevaría recibir en su casa a un nómade, pero está allí por voluntad propia, y el camino proveyó frutos. Aunque le haya costado su salud mental, una desconexión del mundo urbano y más esfuerzos de lo esperado, Baigorria no le es del todo fiel al personaje, no se contagia, se salva de la transferencia ${ }^{5}$ : Baigorria no abandona, no renuncia. Sigue escribiendo hasta el final de la biografía. Y, además, escribió dos libros posteriores, Indiada y Postales de contracultura. Para adelante: Sánchez, lejos de contagiarle el no, potenció la literatura de Baigorria.

\section{Una amistad posible}

22 Tal es la potencia de las notas al pie de la biografía que, aun desde ese lugar, que se supone relegado a lo accesorio y prescindible, se constituyen en disparadores de lo que vendrá. Anthony Grafton señala que la nota al pie es la prueba de que el historiador se ha estudiado todas las fuentes y puede realizar una argumentación con ellas. Las horas de arduo trabajo en el archivo quedan plasmadas en largas anotaciones al pie de página, anotaciones que son vistas, pero no leídas. Intentan demostrar la autoridad de quien escribe el texto, aquel que excavó los cimientos, que profundizó lo suficiente para darle solidez a lo que escribe. Dice Grafton: "la nota al pie, como el retrete, permite a uno realizar tareas desagradables en la intimidad [...]; el buen gusto exige que se la coloque en un lugar discreto [...]. Es el lugar que merece recurso tan baladí: ojos que no ven, corazón que no siente" (1998: 13). Lo paradójico de las notas al pie de la biografía, que no muestran el saber disponible ni sobre la figura de Sánchez ni sobre su obra, es la función nada convencional que adquieren en el texto. Solo aparece un resumen "prensado" de la vida de Sánchez en la nota dos, y el resto es Baigorria escribiendo sobre sí, quejándose de lo costoso de la investigación, o tentado de dejar de escribir. Lejos de esconderlas, constituyen un capítulo para que el lector esté obligado a pasar por allí, para que las lea. No son un recurso biográfico, son parte de la biografía, así como Sánchez es parte de la vida de Baigorria.

Postales de contracultura. Un viaje a la costa oeste 1974-1984 se publica seis años después que Sobre Sánchez. Las capturas fotográficas de una vieja Pentax dan inicio a un relato como ejercicio de memoria que recorre las aventuras de Baigorria por los caminos del norte. Indiada se publica en el mismo año y lo conforman cinco cuentos con mezcla de crónica en los que todo es experimental, excesivo y delirante. Baigorria puede escribir Postales de Contracultura porque escribió Sobre Sánchez; o mejor, Baigorria escribe Postales porque está poseído de pies a cabeza por la figura de Sánchez. El narrador de uno es el mismo que el narrador del otro, la diferencia es que el primero elige la primera del plural para 
contar las mismas anécdotas (los viajes, la sexualidad, la aventura): "Está contado en mi libro Sobre Sánchez con un yo y ahora va con un nos" (2018a: 26) Escribió Indiada con las mismas inquietudes con las que escribió Sobre Sánchez (el género cuento pierde la forma, el trabajo es con fiaca y el azar lo ayuda): “Aunque también podría llamarlos relatos, palabra más abarcadora, prudente y adecuada a mi vacilación para designar textos que no llegan a ser ni novelita, ni nouvelle ni novelette". (2018b: 7)

La identificación amorosa entre biógrafo y biografiado implica, como hemos visto, dos movimientos: la fuerza que ata al biógrafo con su sujeto es la misma que lo va a liberar. En un primer movimiento, Baigorria se enreda emocionalmente con Sánchez y abundan los peligros que describe Edel -la resistencia a descubrir verdades desagradables, y cierta tendencia a alterar los materiales- pero, en el correr de la escritura, el amor a la vida predomina por sobre el amor al personaje. El biógrafo se enreda, sí, pero en el mismo movimiento, se desata para dejarse acompañar sabiendo que puede serle infiel. La traición inherente al envolvimiento emocional lo empuja a Baigorria a continuar escribiendo. "La biografía - dijo Maurois-se escribirá con mayor emoción natural [...] porque los sentimientos y aventuras del héroe serán el instrumento de los propios sentimientos del biógrafo. Hasta cierto punto, será una autobiografía disfrazada de biografía" (citado en Edel 1990: 57).

Dicho esto, si continuamos en la misma línea: el dueño de casa encuentra en su huésped un emancipador. El huésped llega no sólo para desordenar y poner a prueba a su anfitrión, su irrupción también es liberadora; y el biógrafo puede entrar en su propia casa gracias al biografiado. El desvío (del que hablábamos más arriba) supuso que Baigorria se encontrara con eso de sí mismo que desconocía: unas pocas anotaciones sobre algunos recuerdos propios en la escritura de una vida ajena, resultaron ser el capítulo más largo de la biografía. Incluso, si la decisión editorial hubiese sido disponer las notas literalmente al pie del texto, casi que el cuerpo (del texto y de Sánchez) desaparecería de a poco. Sánchez y Baigorria se eligieron sin conocerse, y escribieron en compañía: "Se podría decir que es menos "sobre" que "con" ("junto a") Sánchez" (Baigorria 2012: 7).

El encuentro con Sánchez convoca a Baigorria desde los orígenes de su literatura al mismo tiempo que pertenece por entero al porvenir en tanto el movimiento de la literatura de Baigorria se vio impulsado por el ingreso de Sánchez. Ofrecer hospitalidad implica su repetición. Dejar entrar una vez significa esperar el retorno. Ponerse en el lugar de otro, calzarse sus botas, puede conllevar riesgos y efectos colaterales. Sánchez vio la puerta entreabierta y entró, Baigorria lo recibió para dejarse habitar por otro y encontrarse consigo mismo.

Trato inútilmente de ponerme en su lugar, en sus botas, sobre una isla de barro que en mi imaginación fue como otra tierra prometida: Nueva California. Antes pensaba que el deseo era mi libertad y ahora lo veo parecido a un viento. Un viento que llega sin aviso, que extravía, que lleva por caminos de asombro y te arrastra donde quiere. (90) 


\section{BIBLIOGRAFÍA}

Bachelard, Gastón, La poética del espacio, Buenos Aires, FCE, 2000. Traducción de ernestina de Champourcin

Baigorria, Osvaldo, Anarquismo trashumante. Crónicas de crotos y linyeras, La Plata, Terramar, 2008.

---, Sobre Sánchez, Buenos Aires, Mansalva, 2012.

,--- Postales de contracultura, Buenos Aires, Caja Negra, 2018a.

---,Indiada, Buenos Aires, Blatt y Ríos, 2018 b.

Chitarroni, Luis, Los escritores de los escritores, Buenos Aires, El Ateneo, 1997.

Derrida, Jacques, "Escoger su herencia” en Jacques Derrida y Elizabeth Roudinesco, Y mañana qué, Buenos Aires, FCE, 2003. Traducción de Víctor Goldstein.

---, “Cierta posibilidad imposible de decir el acontecimiento", en Jacques Derrida, Gad Soussana y Alexis Nous, Decir el acontecimiento, ¿es posible?, Arena Libros, Madrid, 2014. Traducción de Julián Santos Gerrero.

---, “Amar de amistad, quizá. El nombre del adverbio", en Políticas de la amistad seguido de El oído de Heidegger, Madrid, Trotta, 1998. Traducción de Patricio Peñalver.

--- y Dufourmantelle, Anne, La hospitalidad, Buenos Aires, De la flor, 2019. Traducción de Mirta Segoviano.

Dufourmantelle, Anne, En caso de amor. Psicopatología de la vida cotidiana, Buenos Aires, Nocturna editora, 2018. Traducción de Karina Macció.

Edel, León, Vidas ajenas. Principia biographica, Buenos Aires, Fondo de Cultura Económica, 1990. Traducción de Evangelina Nuño.

Finkielkraut, Alain y Bruckner Pascal (1979), "La fórmula: Te amo”, en El nuevo desorden amoroso, Barcelona, Anagrama, 1979, p. 135-160. Traducción de Joaquín Jordà.

Finkielkraut, Alain, La sabiduría del amor, Barcelona, Gedisa, 1985. Traducción de Alfredo Báez.

Giordano, Alberto, "El infierno tan temido: imágenes del amor en la literatura de Arlt", en Razones de la crítica. Sobre literatura, ética y política, Buenos Aires, Colihue, 1999, p. 35-56.

Grafton, Anthony, "Notas al pie: el origen de una especie", en Los orígenes trágicos de la erudición: breve tratado sobre la nota al pie de página, Buenos Aires, FCE, 1998.

Musitano, Julia, “Sobre Sánchez, una biografía perezosa”, en Nora Avaro, Judith Podlubne y Julia Musitano (comps.), Un arte vulnerable. La biografía como forma, Rosario, Nube negra, 2018.

Peeters, Benoit (2020), Tres años con Derrida, Buenos Aires: Ubú ediciones. Traducción de Vicenç Tuset.

\section{NOTAS}

1. Según cuenta Baigorria, lo conoció a través de la palabra de un compañero, Benjamin Lardeau, discípulo de Gurdjieff, cuando trabajaba de sembrador de árboles cerca de la frontera de Canadá con Alaska. Benjamin pasaba su tiempo en el bosque dándole consejos a Baigorria sobre cómo 
atravesar grandes esfuerzos físicos con las técnicas del gurú espiritual. “Andá a la puta que te parió, pensaba yo o mi yo inferior. Aunque tengas razón y sea todo cierto. No hay derecho de arruinarle la vida a la gente convenciéndola de tus ideas, meloneando, insistiendo en que tenés la verdad, posta-posta" (110).

2. Baigorria divide la biografía en tres capítulos "Voodoochild", "The Néstor Sánchez experience" y "Notas al pie"; en "About" advierte que las notas al pie también pueden leerse como un tercer capítulo. Esas notas conforman la parte autorreferencial del texto, en la que Baigorria cuenta su experiencia nómade en los Estados Unidos y la variedad de trabajos que le permitieron sobrevivir.

3. Aunque habría que especificar que la tentación de dejar de escribir y abandonar el proyecto es constante a lo largo de todo el libro. La renuncia a la literatura está tematizada no sólo en la biografía sino en otros libros de Baigorria, un lugar en común con Sánchez. Al respecto, véase Musitano 2018.

4. En la posdata de Llévatela, amigo, por el bien de los tres, Baigorria aclara: "La novela que acaban de leer fue tipeada en una máquina Olivetti portátil dentro de un caluroso monoambiente en un octavo piso con dirección nordeste de la calle Chimayo, a media cuadra de Avenida Rivadavia, en el verano de 1988. No había aire acondicionado, no había televisión, no había internet ni otra pantalla móvil o fija para anclar la mirada" (135). En Postales de contracultura: "Escribí buena parte de este libro en pleno verano ardiente de 2018 mientras había cortes de luz en los barrios de Buenos Aires, con más de 100 mil afectados. Por momentos, me salvaba del corte en este departamento de un solo ambiente en Boedo, con otras zonas oscuras y el ascensor sin funcionar" (172).

5. Aquí debería reformular mi artículo anterior: "La transferencia fue total: el abandono persigue también la escritura de Baigorria. A pesar de preferir no hacerlo, de verse sometido al sinfín de inconvenientes que le provocó la investigación sobre Sánchez no pudo dejarla y continuó hasta terminar (a medias porque, desde su punto de vista, no pudo escribir esa biografía que hubiese querido ni contar la auténtica experiencia de Sánchez)" (2018: 175). Me corrijo, el contagio no fue total. Si eso hubiese pasado, no habría relato, Baigorria no habría podido contar lo que quiso contar - por qué Sánchez dejó de escribir-. Que la biografía adquiera una forma dispersa, que las notas al pie desborden el relato sobre lo ajeno, y que la investigación no haya sido la de la biografía convencional, muestran que el biografiado marca el ritmo y acompaña de cerca. Eso hace a la singularidad de Sobre Sánchez.

\section{RESÚMENES}

Para Osvaldo Baigorria, no fue gratuito escribir la biografía de Néstor Sánchez. Hacia atrás y por venir, la literatura de Baigorria sufrió un proceso de transformación. Hacia atrás: Baigorria revisa viejas categorías con las que trabajaba para "amigarse" con Sánchez y poder escribir sobre él. Por venir: todo lo que escribe Baigorria después de la biografía (Postales de contracultura e Indiada) está atravesado por la figura de Sánchez. Por eso, me interesa rastrear cuáles son los rasgos que hicieron posible una amistad entre Sánchez y Baigorria, y los motivos por los que la literatura de uno se ve contaminada por la literatura de otro cuando la vida se atraviesa. Propongo una lectura de la biografía en clave amorosa conforme con el modo en que postulo el vínculo entre biógrafo y biografiado. 
Pour Osvaldo Baigorria, écrire la biographie de Néstor Sánchez ne s'est pas fait sans frais. La littérature de Baigorria a subi un processus de transformation en arrière et en avant. En arrière : Baigorria revisite les anciennes catégories avec lesquelles il a travaillé pour "se lier d'amitié" avec Sánchez et pouvoir écrire sur lui. En avant : tout ce que Baigorria écrit après la biographie (Postales de contracultura et Indiada) est traversé par la figure de Sánchez. C'est pourquoi je m'intéresse aux traits qui ont rendu possible une amitié entre Sánchez et Baigorria, et aux raisons pour lesquelles la littérature de l'un est contaminée par la littérature de l'autre quand la vie y est croisée. Je propose une lecture de la biographie en clé amoureuse selon la manière dont je postule le lien entre biographe et biographe.

For Osvaldo Baigorria, it was not free to write the biography of Néstor Sánchez. Backwards and forwards, Baigorria's literature underwent a process of transformation. Backwards: Baigorria revisits old categories with which he worked to "befriend" Sánchez and be able to write about him. Forwards: everything that Baigorria writes after the biography (Postales de contracultura and Indiada) is crossed by the figure of Sánchez. That is why I am interested in tracing the features that made a friendship between Sánchez and Baigorria possible, and the reasons why one's literature is contaminated by the literature of the other when life gets in the way. I propose a reading of the biography in a loving key in accordance with the way I postulate the link between biographer and biographer.

\section{ÍNDICE}

Mots-clés: Biographie, amour, amitié, biographe, biographie

Palabras claves: Biografía, amor, amistad, biógrafo, biografiado

Keywords: Biography, love, friendship, biographer, biography

\section{AUTOR}

JULIA MUSITANO

IECH, UNR - CONICET

musitanoj@gmail.com 